\title{
THE INTERACTION OF HUMAN ERYTHROCYTES WITH SODIUM PALMITATE
}

\author{
By DEWITT S. GOODMAN \\ (From the Laboratory of Cellular Physiology and Metabolism, National Heart Institute, \\ National Institutes of Health, Bethesda, Md.)
}

(Submitted for publication June 6, 1958; accepted July 31, 1958)

Evidence has recently been acquired that the unesterified fatty acids (UFA) present in human blood plasma are of great metabolic significance, apparently functioning as a transport form of lipid readily available as a substrate for oxidation. This evidence includes studies of UFA arteriovenous differences and studies of the responsiveness of plasma UFA concentration to changes in dietary status and to the administration of hormones (1-3). Furthermore, turnover studies have demonstrated an extremely rapid turnover of this lipid fraction. After intravenous injection of $\mathrm{C}^{14}$-labeled UFA, plasma activity declined with initial half-times of two to three minutes in the fasting human subject $(4,5)$, and with even shorter half-times in the rat (6) and the $\operatorname{dog}(7)$. In these studies, labeled $\mathrm{CO}_{2}$ was found in expired air within minutes after the injection of labeled UFA and, in the human subject, reached its peak specific activity in about 30 minutes (5).

Quantitative investigations of the interaction of unesterified fatty acids with human serum albumin and with human lipoproteins have revealed the fatty acids to be tightly bound by these proteins, particularly by albumin $(8,9)$. On the basis of albumin binding alone it has been estimated that in normal human plasma less than 0.01 per cent of plasma UFA exists free (unbound) in solution (8). The problem therefore emerges of the mechanism whereby plasma UFA, which exists tightly bound to serum albumin, is rapidly transported to intracellular loci of oxidation (mitochondria), with the extremely rapid turnover described above. One suitable hypothesis would be to postulate the existence of receptor sites on cell surfaces which are able to bind UFA tightly enough to compete with serum albumin. Such sites, if capable of exchanging UFA rapidly, could serve as intermediates in the transfer of plasma UFA from serum albumin to intracellular loci. In order to test this hypothesis the interaction of human erythrocytes with a long-chain fatty acid salt, sodium palmitate, has been studied by measuring the distribution of the fatty acid between erythrocytes and serum albumin. The results of these studies are reported herein.

\section{MATERIALS AND METHODS}

Materials. Palmitic acid of high purity was supplied by the Hormel Institute. Its melting point was 63 to $64^{\circ} \mathrm{C}$. (literature, 63 to $64^{\circ}$ ). Palmitic acid-1-C 14 was obtained from the Nuclear Instrument and Chemical Corporation of Chicago. Its specific activity was $2.45 \mathrm{mc}$. per mM. Counter-current distribution of this material in a 25 tube system, by the method of Ahrens and Craig (10), revealed the presence of 4 to 5 per cent of the radioactivity in a peak of much greater polarity than the main body of the material; this was presumed to represent a short-chain fatty acid impurity. The rest of the radioactivity distributed itself in a single symmetrical peak. The palmitic acid-1-C ${ }^{14}$ was partially purified before use (after analysis) by dissolving it in a 1:1 mixture of isooctane-glacial acetic acid, adding one-tenth volume water to achieve separation into two phases, and discarding the acetic acid phase. This procedure removes most of the short-chain fatty acids from a mixture of short- and long-chain fatty acids (11).

Solutions of sodium palmitate (unlabeled) and sodium palmitate-1-C 14 were prepared as previously described (12). The concentration of the unlabeled sodium palmitate solution was determined gravimetrically and verified by titration (12); other solutions were made from the initial one by dilution. The concentration of the sodium palmitate1-C $\mathrm{C}^{14}$ solution was determined from its concentration of radioactivity and specific activity, using the calibration standards of this laboratory.

The UFA-poor human serum albumin used in these experiments was identical with a previously described preparation (13). This albumin was a sample of Fraction V of Cohn, the long-chain fatty acid content of which had been reduced to $0.1 \mathrm{M}$ per $\mathrm{M}$ or less by extracting the lyophilized protein with 5 per cent glacial acetic acid in isooctane. Albumin solutions were freshly prepared for each experiment by dissolving some of the lyophilized protein (stored at $-10^{\circ}$ ) in distilled water. The concentration of each solution was determined by comparing its optical density at $279 \mathrm{~m} \mu$ as read in a Beckman quartz 
spectrophotometer to the optical density of a standard albumin solution whose concentration had been determined by Kjeldahl analysis for nitrogen. Sixty-nine thousand was taken as the molecular weight of albumin for the calculation of molar concentrations.

Slightly outdated normal whole blood which had been collected in acid-citrate-dextrose (ACD) solution was obtained from the Blood Bank of the Clinical Center. After removal of the plasma, the red cells were twice washed by

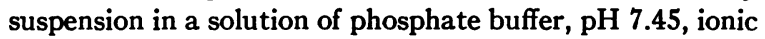
strength $0.160(0.061 \mathrm{M})$, which was also $0.077 \mathrm{M}$ in $\mathrm{NaCl}$. This solution of phosphate buffer- $\mathrm{NaCl}$ is isotonic with respect to plasma. The concentration of red cells in the final preparation (in units of millions of red cells per cu. $\mathrm{mm}$.) was determined by counting the red cells in two chambers of a conventional hemacytometer.

Red cell ghosts were prepared by dilution hemolysis according to the method of Ponder (14). The final preparation of ghosts was suspended in a total volume equal to the volume of packed red cells used in its preparation. An estimated loss of approximately 30 per cent occurred during the process of preparing the ghosts. The concentration of ghosts in the final preparation was hence taken as seven-tenths times the initial concentration of red cells. This estimate is in no way critical in the calculations.

Phosphate buffer was prepared as a stock solution of 10 times the desired ionic strength; dilution of this solution 1 in 10 resulted in a solution of $\mathrm{pH} 7.45$ and ionic strength 0.160 .

Method. The experimental technique employed consisted in the equilibration of increasing quantities of sodium palmitate in a mixture of equal volumes of the preparation of red cells (or ghosts) and a solution of serum albumin in isotonic phosphate buffer- $\mathrm{NaCl}$. Equilibration was conducted in a series of ground glass stoppered $50 \mathrm{ml}$. centrifuge tubes. To each tube were added $2 \mathrm{ml}$. of the serum albumin solution, $1 \mathrm{ml}$. of the stock concentrated phosphate buffer, $1 \mathrm{ml}$. of a solution of $0.770 \mathrm{M} \mathrm{NaCl}, 1 \mathrm{ml}$. of the sodium palmitate-1-C14 solution, 0 to $5 \mathrm{ml}$. of an unlabeled sodium palmitate solution, and enough distilled water to make a total volume of $10 \mathrm{ml}$. The final concentration of serum albumin was slightly greater than $1 \times 10^{-4}$ $M$ per L. The total quantity of fatty acid in each series of tubes ranged over more than one order of magnitude. To each tube $10 \mathrm{ml}$. of the red cell (or ghost) preparation was then added, and the tubes equilibrated by being gently tilted back and forth, at the rate of 30 times per minute, for one hour. It was found that equilibration was more than 95 per cent complete at one hour, as compared to six hours. The tubes were then centrifuged for 20 minutes at $1,500 \mathrm{rpm}$ and the clear albumin solutions carefully drawn off. The packed red cells (or ghosts) were washed three times by suspension in $10 \mathrm{ml}$. of isotonic phosphate buffer- $\mathrm{NaCl}$ solution, followed by centrifugation. All experiments were conducted in an air conditioned laboratory at $23 \pm 1^{\circ} \mathrm{C}$.

After equilibration, the albumin solutions and the washed red cells were analyzed as follows. In the experiments with intact red cells, measured aliquots of each albumin solution and each red cell phase were lyophilized, and extracted with $25 \mathrm{ml}$. of a 1:1 mixture of isooctane-glacial acetic acid. The mixtures were then split into two phases and the isooctane phases washed according to the method of Gordon (3). Aliquots of the isooctane phases (containing all the palmitic acid) were measured into small vials and evaporated to dryness. In the experiments with ghosts, aliquots of the albumin solutions and the ghosts were extracted with 25 volumes of a solution of ethanol: acetone $(1: 1)$, and portions of the extraction solutions measured into vials and evaporated to dryness. ${ }^{1}$ To each vial (in both the red cell and ghost experiments) was then added $15 \mathrm{ml}$. of a scintillation solution consisting of $400 \mathrm{mg}$. per cent diphenyloxazole (DPO, Pilot Chemicals Inc.) in toluene. The concentration of radioactivity in each vial was measured with a Packard Liquid Scintillation Spectrometer (efficiency, ca. 60 per cent; background, $c a .15$ cpm). Enough counts were recorded so that the standard error of each measurement was 1 per cent or less. From these measurements the total number of cpm associated with each albumin solution and each red cell phase was calculated. The total recovery of $\mathrm{cpm}$ was within 5 per cent of the expected recovery in each tube. The total number of moles of palmitate associated with each albumin solution and each red cell phase was then calculated as the per cent of recovered cpm times the known amount of palmitate added to each tube. The average number of moles of palmitate bound per $10^{6}$ red cells was calculated by dividing the number of moles of palmitate found in each red cell phase by the measured number of red cells in millions. Finally, the average number of palmitate ions bound per albumin molecule, $\bar{\nu}$, was determined by dividing the number of moles of palmitate in each albumin solution by the number of moles of albumin present. This calculation assumes that all the palmitate in the albumin solution was bound to the protein; the results of a previous study (8) indicate that the error in this assumption is less than 1 per cent at all concentrations herein employed.

\section{RESULTS}

\section{A. Intact red cells}

The results of the experiments with intact red cells are presented in Table I and are shown graphically as the solid circles in Figure 1, in which $\bar{\nu}$, the average number of moles of palmitate bound per mole of serum albumin, is plotted against the number of moles of palmitate bound per $10^{6}$ red cells. Inspection of Table I reveals that in the concentrations employed a significant fraction of the palmitate was bound by the red cells. The fraction of palmitate bound by the

1 The more laborious extraction procedure was employed in the experiments with red cells in order to be able to titrate the UFA concentration of the albumin solutions (vide infra). This was not done in the experiments with ghosts. 
TABLE I

Binding of palmitate by albumin and erythrocytes in vitro

\begin{tabular}{|c|c|c|c|c|c|c|c|}
\hline \multirow{2}{*}{$\begin{array}{c}\text { Tube } \\
\text { no.* }\end{array}$} & \multirow{2}{*}{$\begin{array}{l}\text { \% of total } \\
\text { cpm with } \\
\text { RBC'8 }^{\prime}\end{array}$} & \multirow{2}{*}{$\begin{array}{c}\text { Total } \\
\text { palmitate } \\
\text { added }\end{array}$} & \multicolumn{2}{|c|}{$\begin{array}{l}\text { Palmitate in each } \\
\text { phase at equilibrium }\end{array}$} & \multirow{2}{*}{$\begin{array}{l}\bar{y} \text { to } \\
\text { HSA }\end{array}$} & \multirow{2}{*}{$\begin{array}{c}\text { Palmitate bound } \\
\text { to } \mathrm{RBC}_{8}\end{array}$} & \multirow{2}{*}{$\begin{array}{c}\text { Measured } \\
\text { total UFA } \\
\text { in HSA } \\
\text { phase }\end{array}$} \\
\hline & & & HSA & RBC & & & \\
\hline & & $\mu M$ & \multicolumn{2}{|c|}{$\mu M$ calculated } & & $M / 10^{\circ} R B C$ & $\mu M$ \\
\hline $\begin{array}{l}1 \\
2 \\
3 \\
4 \\
5 \\
6 \\
7 \\
8\end{array}$ & $\begin{array}{l}5.79 \\
9.45 \\
14.8 \\
21.1 \\
22.3 \\
27.6 \\
32.7 \\
36.1\end{array}$ & $\begin{array}{c}0.82 \\
1.41 \\
2.58 \\
3.75 \\
4.72 \\
5.70 \\
7.65 \\
10.6\end{array}$ & $\begin{array}{l}0.77 \\
1.28 \\
2.20 \\
2.96 \\
3.67 \\
4.12 \\
5.15 \\
6.75\end{array}$ & $\begin{array}{l}0.047 \\
0.13 \\
0.38 \\
0.79 \\
1.05 \\
1.58 \\
2.50 \\
3.82\end{array}$ & $\begin{array}{l}0.68 \\
1.13 \\
1.96 \\
2.61 \\
3.24 \\
3.64 \\
4.54 \\
5.96\end{array}$ & $\begin{array}{l}0.049 \times 10^{-11} \\
0.14 \times \times 10^{-11} \\
0.40 \times 10^{-11} \\
0.83 \times \times 10^{-11} \\
1.10 \times 10^{-11} \\
1.66 \times 10^{-11} \\
2.62 \times 10^{-11} \\
4.00 \times 10^{-11}\end{array}$ & $\begin{array}{l}0.5 \\
1.1 \\
1.7 \\
2.5 \\
3.4 \\
3.6 \\
5.2 \\
6.1\end{array}$ \\
\hline
\end{tabular}

* Each tube contained $1.13 \times 10^{-6} \mathrm{M}$ of human serum albumin (HSA) and $9.54 \times 10^{10}$ red blood cells (RBC).

red cells is small at values of $\bar{\nu}$ below 2 , but increases steadily as the total amount of palmitate present increases.

Calculation of the number of binding sites and their association constants. Scatchard and coworkers have shown (15-17) that the binding of an anion, A, to several classes of sites on a protein molecule may be formulated as:

$$
\bar{\nu}_{\mathrm{A}}=\sum_{\mathbf{i}} \bar{\nu}_{\mathrm{Ai}}=\sum_{\mathbf{i}} \frac{\mathrm{n}_{\mathrm{i}} \mathrm{k}_{\mathrm{Ai}}^{\prime} \mathrm{C}_{\mathrm{A}}}{1+\mathrm{k}_{\mathrm{Ai}}^{\prime} \mathrm{C}_{\mathbf{A}}}
$$

in which $\mathrm{k}_{\mathbf{A} \text { i }}^{\prime}$ is the apparent association constant for each of the $n_{i}$ sites in class $i$ under any particular set of conditions, and $c_{A}$ is the free (unbound) concentration of $A$ in equilibrium with the protein. The apparent association constant, $\mathbf{k}_{\mathbf{A i}}^{\prime}$, is valid only for the particular experimental conditions employed (ionic strength, $\mathrm{pH}$, temperature, and so forth), and is related to the

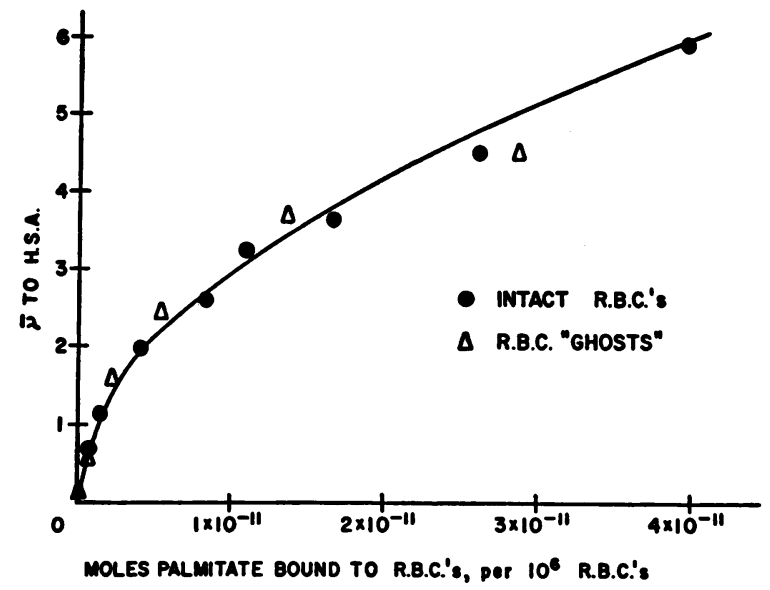

Fig. 1. Relationship of Palmitate Binding by Erythrocytes to Binding by Serum Albumin intrinsic association constant, $\mathrm{k}_{\mathrm{Ai}}^{\mathbf{0}}$, by a number of factors which correct for the effects of electrostatic interactions, competition with other ions, and the hydrogen ion equilibrium of the binding sites. These factors have been discussed in detail elsewhere (8).

In a recent publication, quantitative studies of the interaction of human serum albumin with several long-chain fatty acid anions were reported (8). The fatty acids studied included lauric, myristic, palmitic, stearic, oleic and linoleic acids. The conditions employed ( $\mathrm{pH} 7.45,23^{\circ} \mathrm{C}$., phosphate buffer, ionic strength 0.160 ) were identical with the conditions used in the present studies, except for the additional presence of $\mathrm{NaCl}$ in the present experiments (to make the solutions isotonic; ionic strength 0.24$).^{2}$ Analysis of the data in terms of Equation 1 revealed that in every case there were three classes of sites which bound the fatty acid anions on the serum albumin molecule. The number of sites in each class were: $\mathrm{n}_{1}=2, \mathrm{n}_{2}=5, \mathrm{n}_{3}=20$. There are therefore a total of 27 sites on the serum albumin molecule which are able to bind fatty acid anions. Of these, two sites bind fatty acids extremely tightly, five sites somewhat less tightly, and the remaining binding sites are relatively weak.

In the same study, the values of the association constants for each class of sites were reported for each fatty acid studied. The values of these constants for palmitate are: $\mathrm{k}_{1}{ }^{\prime}=6.0 \times 10^{7}$;

2 The addition of this much $\mathrm{NaCl}$ has very little effect on palmitate binding to serum albumin (unpublished observations) and has been neglected in the subsequent analysis. 
$\mathrm{k}_{2}{ }^{\prime}=3.0 \times 10^{6} ; \mathrm{k}_{3}{ }^{\prime}=1 \times 10^{3} .^{3} \quad$ Substituting these values of $k^{\prime}$ and the above values of $n$ into Equation 1 therefore yields the following expression for palmitate binding to serum albumin :

$\bar{\nu}=\frac{1.2 \times 10^{8} \mathrm{c}}{1+6 \times 10^{7} \mathrm{c}}+\frac{1.5 \times 10^{7} \mathrm{c}}{1+3 \times 10^{6} \mathrm{c}}+\frac{2 \times 10^{4} \mathrm{c}}{1+10^{3} \mathrm{c}}$.

Let us now consider the present experiments, in which the distribution of palmitate between red cells and serum albumin has been measured at a number of different values of $\bar{\nu}$. From these data one can determine the number of sites on red cells which are able to bind palmitate ions, and the tightness of this binding (i.e., the association constants). This was done as follows:

It was first assumed that there is a single class of sites on the red cells which is able to bind palmitate ions; this assumption will be validated below. If we then let $\mathrm{R}$ be the number of moles of binding sites per $10^{6}$ red cells, and $k_{r}{ }^{\prime}$ be the apparent association constant for each site, the application of Equation $1^{4}$ yields the binding equation:

$$
\overline{\mathrm{y}}=\frac{\mathrm{Rk}_{\mathrm{r}}{ }^{\prime} \mathrm{c}}{1+\mathrm{k}_{\mathrm{r}}^{\prime} \mathrm{c}}
$$

in which $\bar{y}$ is the average number of moles of palmitate bound per $10^{6}$ red cells. Solving for c in Equation 3 and substituting this expression for $\mathrm{c}$ into Equation 2 then yields an equation relating the experimentally measured quantities, $\bar{\nu}$ and $\bar{y}$, to the two unknowns, $R$ and $k_{r}{ }^{\prime}$,

$$
\begin{gathered}
\bar{\nu}=\frac{1.2 \times 10^{8} \overline{\mathrm{y}}}{\mathrm{Rk}_{\mathrm{r}}{ }^{\prime}+\overline{\mathrm{y}}\left(6 \times 10^{7}-\mathrm{k}_{\mathrm{r}}{ }^{\prime}\right)} \\
+\frac{1.5 \times 10^{7} \overline{\mathrm{y}}}{\mathrm{Rk}_{\mathrm{r}}{ }^{\prime}+\overline{\mathrm{y}}\left(3 \times 10^{6}-\mathrm{k}_{\mathrm{r}}{ }^{\prime}\right)} \\
+\frac{2 \times 10^{4} \overline{\mathrm{y}}}{\mathrm{Rk}_{\mathrm{r}}{ }^{\prime}+\overline{\mathrm{y}}\left(10^{3}-\mathrm{k}_{\mathrm{r}}{ }^{\prime}\right)}
\end{gathered}
$$

By the method of successive approximations, the values of $R$ and $k_{r}{ }^{\prime}$ which would best fit the experimental data were then determined. These values are: $\mathrm{R}=5.3 \times 10^{-11} ; \mathrm{k}_{\mathrm{r}}{ }^{\prime}=2.2 \times 10^{6}$.

\footnotetext{
${ }^{3}$ As discussed in Reference 8, the values of $n_{2}$ and $\mathbf{k}_{2}{ }^{\prime}$ are known with less precision than those of $n_{1}$ and $k_{1}{ }^{\prime}$, and the values of $n_{3}$ and $k_{3}{ }^{\prime}$ are to be regarded as only little more than approximations.

- Equation 1 is just a special form of the mass action expression and is equally valid for red cells as for proteins, so long as equilibrium exists between bound and free small (palmitate, here) ions and units are properly chosen.
}

The closeness with which these values describe the experimental data can be seen by inspection of Figure 1. The solid curve drawn in this figure is a plot of Equation 4, using these values of $R$ and $k_{r}{ }^{\prime}$. The fact that such a good fit can be obtained with a plot of Equation 4 validates the initial assumption that there is a single class of binding sites on the red cells. If there were two or more different classes of sites it would be impossible to find values of $R$ and $k_{r}{ }^{\prime}$ which would result in a plot of Equation 4 which would give nearly this close a fit. In addition, it should be pointed out that the distribution of the experimental data is such that the solution of Equation 4 for $R$ and $k_{r}{ }^{\prime}$ is almost unique.

\section{B. Red cell ghosts}

The results of the experiments using red cell ghosts instead of intact red cells are also plotted in Figure 1, as open triangles. The results obtained with the ghosts are very similar to those obtained with intact red cells. It is hence apparent that the ability of red cells to bind palmitate ions is a property of the ghosts, and that the binding sites discussed above must be located in the ghosts.

\section{Effect of inhibition of red blood cell metabolism}

In order to treat red cell binding of palmitate ions as a simple chemical equilibrium reaction, it is necessary to demonstrate that this binding is not dependent upon the metabolic activity of the cell, but rather only requires the intact configuration of the binding sites. This was done by preparing two duplicate tubes (with intact red cells) and adding to one of them $\mathrm{KCN}$, to give a final concentration of $0.02 \mathrm{M}$, and 2-deoxyD-glucose (Aldrich Chemical Corp.) to give a final concentration of $30 \mathrm{mg}$. per $\mathrm{ml}$. This quantity of 2-deoxy-D-glucose is enough to inhibit the glycolysis of whole blood by more than 90 per cent (18). The distribution of palmitate between serum albumin and red cells was then measured as described above. The binding of palmitate by the red cells was found to be identical in the two tubes, with 38.1 per cent of the palmitate bound to the red cells in the tube without the $\mathrm{CN}^{-}$and deoxy-glucose, and 38.6 per cent bound to the red cells in the tube with these additions. 


\section{Chemical analysis of the bound palmitate}

Analyses were performed to demonstrate that the labeled palmitate extracted from the red cells after equilibration was still present as an unesterified fatty acid. Aliquots of several of the isooctane extracts of the red cells were combined, and the phospholipids adsorbed onto a silicic acid column (19). ${ }^{5}$ The remainder of the extract was separated into neutral lipid and unesterified fatty acid fractions by using the solvent partition method of Borgstrom (20). The phospholipids were eluted from the silicic acid column with absolute methanol. The three fractions (phospholipids, neutral lipids and unesterified fatty acids) were then separately analyzed for radioactivity. The total recovery of radioactivity in the three fractions was 95 per cent. Of this, only 1.2 per cent was found in the neutral lipid fraction, and 2.5 per cent in the phospholipid fraction. These figures are within the limits of error of the techniques employed, and demonstrate that essentially all the labeled material recovered from the red cells was still present as unesterified fatty acid.

An experiment was also performed to rule out the possibility that some of the palmitate found in the washed red cells was still bound to albumin. An equilibration tube was prepared in the usual manner, and to it was added $0.3 \mu \mathrm{c}$. of $\mathrm{I}^{131}$ labeled albumin (RISA ${ }^{\circledR}$, Abbott). After equilibration the red cells were analyzed for both $\mathrm{C}^{14}$ and $\mathrm{I}^{131}$ activity. $\mathrm{I}^{131}$ activity was measured in a well-type scintillation counter. It was found that whereas 34.1 per cent of the $\mathrm{C}^{14}$ activity was present in the red cells, only 0.3 per cent of the $\mathrm{I}^{131}$ activity was present in the red cells. This indicated that a negligible quantity of albumin was present in the washed red cells, and that the palmitate found there was indeed bound to the red cells.

\section{E. Further measurements}

A final check of the validity of the formulations described above was undertaken by titrating aliquots of the isooctane extracts of the albumin solutions for UFA content, using the method of Gordon (3). The results of these titrations were

- This was kindly performed by Dr. D. Frederickson and $\mathrm{Mr}$. K. Ono. then converted to total micromoles of UFA present in each albumin solution, and are listed in the last column of Table I. If the formulations herein employed are correct, these values should correspond to the palmitate content as calculated from the distribution of radioactivity These latter values are listed in the fourth column of Table I. It can be seen that the agreement is fairly good, with the measured values varying between 75 and 100 per cent of the calculated values. Most of the variation probably resulted from the experimental error of the UFA titrations, which was $\pm 0.4 \mu \mathrm{M}$ UFA per solution in these experiments. These results clearly eliminate the possibility of some gross error being involved in the analytic formulations, such as would occur if the labeled palmitate found in the red cells resulted from an exchange reaction between the palmitate of the solution and some acidic component of the red cells. The treatment of the data in terms of a distribution of palmitate between the binding sites of albumin and red cells is therefore validated.

\section{DISCUSSION}

The experimental results presented above demonstrate that human erythrocytes interact strongly with large numbers of palmitate ions, and that this interaction can be described by a mass action expression. It has also been shown that the binding sites are located on the red cell ghost, and that the binding reaction is independent of the metabolic activity of the cell. Analysis in terms of a single class of binding sites has revealed that there are $5.3 \times 10^{-11} \mathrm{M}$ of binding sites per $10^{6}$ red cells, and that the apparent association constant for each of these sites is $2.2 \times 10^{6}$. This number of moles of binding sites per $10^{6}$ red cells can be converted to an equivalent value of $3.2 \times 10^{7}$ binding sites per single red cell, by multiplying by Avogadro's Number and dividing by $10^{6}$. Furthermore, if we divide this number by the average surface area of a normal red cell, $135 \mu^{2}(21)$, we arrive at a value for the surface density of binding sites, namely that there is one binding site per 420 square angstroms of red cell surface. These figures show that red blood cells possess an extremely large capacity for binding palmitate ions.

The value of the association constant for the 
red cell binding sites is very close to that of the second class of binding sites on serum albumin $\left(3.0 \times 10^{6}\right)$. The red cell sites can hence compete with the second class of albumin binding sites on an almost equal basis. The association constant for the first class of albumin binding sites is, however, more than an order of magnitude greater than this. The red cells cannot therefore effectively compete with serum albumin until the first class of albumin binding sites is saturated (i.e., until $\bar{\nu}$ is 2 or more). In normal human plasma the concentrations of both serum albumin and unesterified fatty acids are close to $5 \times 10^{-4} \mathrm{M}$ per $\mathrm{L}$. This corresponds to a value of $\bar{\nu}$ of 1 . If we assume that all the unesterified fatty acids behave similarly to palmitate, we find, from Figure 1, that the corresponding number of moles of UFA bound per $10^{6}$ red cells is $0.13 \times 10^{-11}$. Multiplying by the normal level of red cells in whole blood then indicates that normally only 1 to 2 per cent of the UFA will exist bound to red blood cells.

The demonstration of a high density of potent binding sites on the red cell ghost provides experimental support for the hypothesis that the initial step in plasma UFA metabolism involves the transfer of UFA from serum albumin to receptor sites on cell surfaces. In order for this hypothesis to be correct it is only necessary that there be a large number of rapidly turning over binding sites with association constants within one or two orders of magnitude of the albumin association constants. Under physiologic in vivo conditions a true chemical equilibrium is probably never achieved between the binding sites on serum albumin and on cell surfaces, because fatty acids bound to the cell surfaces are probably rapidly transferred inside the cells. The turnover rate of these binding sites is hence extremely important and may, in fact, be the limiting factor in plasma UFA turnover. Nothing is known about the turnover rate of these binding sites, or about the subsequent steps whereby the fatty acids are brought within the cells and to mitochondrial loci of oxidation. These later steps may involve enzymatic processes such as activation, but there are other equally feasible mechanisms which might be postulated.

A similar concept of fatty acid uptake by tissues has been advanced by Fillerup, Migliore and Mead (22), who measured the absorption of palmitate-1-C $\mathrm{C}^{14}$ by ascites tumor cells in the presence of serum albumin. They found that in the presence of enough $\mathrm{KCN}$ to inhibit the respiration of the cells, a large percentage of the labeled palmitate was found associated with the cells. This indicated that the cells could absorb palmitate from an albumin solution in the absence of cell respiration. They suggested that this process of absorption is one of passive partition between the medium and the cell surface. Their experiments did not differentiate, however, between surface and internal binding of palmitate on the part of the tumor cells.

It is true, of course, that red blood cells are atypical cells, and that results obtained with red cells cannot be unreservedly applied to other cells. Red cells were selected because of the ease with which they can be studied in a truly quantitative fashion, and because of the fact that the surface membrane and its associated components (the ghost) can be obtained separately. If one assumes, however, that other tissue cells have a density of binding sites and association constants at all approaching the values found for red cells, the reasonableness of the above hypothesis becomes apparent. The total surface area of tissue cells adjacent to capillaries is much larger than the total red blood cell surface area. It is thus easy to visualize how a large fraction of the plasma UFA could be removed by surface binding sites of tissues, in a single circulation through the tissues. If the fatty acids are able to be transferred inside the cells with great rapidity, the observed very rapid turnover times become understandable. In any event, further studies of this kind using other tissues should provide insight into the details of the mechanisms of unesterified fatty acid metabolism.

\section{SUMMARY}

The interaction of human erythrocytes with sodium palmitate has been studied by measuring the distribution of varying quantities of palmitate between human erythrocytes and human serum albumin. The conditions employed were isotonic phosphate buffer- $\mathrm{NaCl}, \mathrm{pH} 7.45$, ionic strength $0.24,23^{\circ} \mathrm{C}$. Analysis of the results in terms of a single class of binding sites on the erythrocytes has revealed that there are $5.3 \times$ 
$10^{-11} \mathrm{M}$ of binding sites per $10^{6}$ erythrocytes, and that the apparent association constant for each of these sites is $2.2 \times 10^{6}$. This number of binding sites is equivalent to $3.2 \times 10^{7}$ binding sites per erythrocyte. It has also been shown that the binding sites are located on the erythrocyte ghosts, and that the binding reaction is independent of the metabolic activity of the cell. The results have been discussed in terms of the hypothesis that the initial step in plasma unesterified fatty acid metabolism involves the transfer of unesterified fatty acids from serum albumin to receptor binding sites on cell surfaces.

\section{REFERENCES}

1. Gordon, R. S., Jr., and Cherkes, A. Unesterified fatty acid in human blood plasma. J. clin. Invest. 1956, 35, 206.

2. Dole, V. P. A relation between non-esterified fatty acids in plasma and the metabolism of glucose. J. clin. Invest. 1956, 35, 150.

3. Gordon, R. S., Jr. Unesterified fatty acid in human blood plasma. II. The transport function of unesterified fatty acid. J. clin. Invest. 1957, 36, 810.

4. Laurell, S. Turnover rate of unesterified fatty acids in human plasma. Acta physiol. scand. 1957, 41, 158.

5. Fredrickson, D. S., and Gordon, R. S., Jr. The metabolism of albumin bound $\mathrm{C}^{14}$-labeled unesterified fatty acids in normal human subjects. J. clin. Invest. 1958, 37, 1504.

6. McCalla, C., Gates, H. S., Jr., and Gordon, R. S., Jr. $\mathrm{C}^{14} \mathrm{O}_{2}$ excretion after the intravenous administration of albumin-bound palmitate-1-C $\mathrm{C}^{14}$ to intact rats. Arch. Biochem. 1957, 71, 346.

7. Fredrickson, D. S., McCollester, D. L., Havel, R. J., and Ono, K. The early steps in the transport and metabolism of exogenous triglyceride and cholesterol in Chemistry of Lipids as Related to Atherosclerosis, I. Page, Ed. Springfield, Ill., Chas. C Thomas, 1958.

8. Goodman, DeW. S. The interaction of human serum albumin with long-chain fatty acid anions. J. Amer. chem. Soc. 1958, 80, 3892.
9. Goodman, DeW. S., and Shafrir, E. The interaction of human low density lipoproteins with long-chain fatty acid anions. J. Am. chem. Soc. In press.

10. Ahrens, E. H., Jr., and Craig, L. C. Separation of the higher fatty acids. J. biol. Chem. 1952, 195, 299.

11. Gordon, R. S., Jr. Unpublished observations.

12. Goodman, DeW. S. The distribution of fatty acids between n-heptane and aqueous phosphate buffer. J. Amer. chem. Soc. 1958, 80, 3887.

13. Goodman, DeW. S. The preparation of human serum albumin free of long-chain fatty acids. Science 1957, 125, 1296.

14. Ponder, E. Hemolysis and Related Phenomena. New York, Grune and Stratton, 1948, p. 116.

15. Scatchard, G. The attraction of proteins for small molecules and ions. Ann. N. Y. Acad. Sci. 1949, 51,660 .

16. Scatchard, G., Scheinberg, I. H., and Armstrong, S. H., Jr. Physical chemistry of protein solutions. IV. The combination of human serum albumin with chloride ion. J. Amer. chem. Soc. 1950, 72, 535.

17. Scatchard, G., Coleman, J. S., and Shen, A. L. Physical chemistry of protein solutions. VII. The binding of some small anions to serum albumin. $\mathrm{J}$. Amer. chem. Soc. 1957, 79, 12.

18. Laszlo, J., Landau, B., Wight, K., and Burk, D. The effect of glucose analogues on the metabolism of human leukemic cells. J. nat. Cancer Inst. 1958, 21, 475. (Also Personal Communication from J. Laszlo.)

19. Borgstrom, B. Investigation on lipid separation methods. Separation of phospholipids from neutral fat and fatty acids. Acta physiol. scand. 1952, 25, 101.

20. Borgstrom, B. Investigation on lipid separation methods. Separation of cholesterol esters, glycerides, and free fatty acids. Acta physiol. scand. 1952, 25, 111.

21. Munn, J. I. Studies of lipids in human erythrocytes. Ph.D. Dissertation, Georgetown University, May, 1957.

22. Fillerup, D. L., Migliore, J. C., and Mead, J. F. The uptake of lipoproteins by ascites tumor cells. The fatty acid-albumin complex. J. biol. Chem. 1958, 233, 98. 